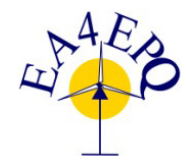

International Conference on Renewable Energies and Power Quality (ICREPQ'14)

Cordoba (Spain), $8^{\text {th }}$ to $10^{\text {th }}$ April, 2014

Renewable Energy and Pourer Quality. Fournal (RE\&PQJ)

ISSN 2172-038 X, No.12, April 2014

\title{
Renewable Energy Cycle with Magnesium and Solar-Energy-Pumped Lasers
}

\author{
T. Yabe ${ }^{1,2}$, Y. Suzuki ${ }^{2}$ and Y. Satoh ${ }^{2}$ \\ ${ }^{1}$ Department of Mechanical Engineering and Sciences \\ Tokyo Institute of Technology \\ 2-12-1 Oh-okayama, Meguro-ku, Tokyo 152-8552 (Japan) \\ Phone/Fax number:+81 3 57342165, e-mail: yabe@mech.titech.ac.jp \\ ${ }^{2}$ Energy Genesis Cycle(EGC) Inc. and EGC-USA Inc. \\ 3-29-8 Kitasennzoku, Ohta-ku, Tokyo 145-0062 (Japan) \\ Phone number:+81 36425 6240, Fax number:+81 364256241 \\ Email: ysuzuki57@gmail.com
}

\begin{abstract}
We report the recent progress of our proposed renewable energy cycle based on magnesium and solar-energypumped laser. The solar energy is used to recycle the used magnesium, $\mathrm{MgO}$, to recover new magnesium and magnesium is used as fuel-cell battery. The batteries for the cell phone, automobiles and others have already been developed and demonstrated. The magnesium of $24 \mathrm{~kg}$ is proven to drive a car for $500 \mathrm{~km}$ without charging.
\end{abstract}

\section{Key words}

Solar Energy, Magnesium, Recycle, Battery, Energy Carrier.

\section{Introduction}

Nowadays typhoon is growing its size and there frequently occurred anomalous atmospheric phenomena. No one can deny that it is a consequence of change of terrestrial environment owing to $\mathrm{CO} 2$ emission. The difference of vaporization between tropical area and northern area leads to the difference of salinity which drives global ocean circulation. There is a movie in which the global warming reduces such salinity difference and finally stops the global circulation and entire American continents are frozen. This is not a science fiction but has solid scientific basis. Some body, who insists there is no global warming but is cooling, may not understand the real picture of Earth which stands with delicate balance.

We are obliged to pass over this Earth to our descendants as it is. We created the system to waste fossil fuels that were formed during millions or billions of years, in only 200 years. We must show how to recover the Earth as soon as possible.

The Earth provided us huge resources of magnesium in the ocean and huge resources should be environment-friendly because we were born from ocean. We show here that magnesium is the best candidate for renewable energy sources [1].

\section{How to Store the Solar Energy?}

There exist several candidates for storing the solar energy or other energy. However, it is important to note that three major points must be cleared. (1) It must be transportable, (2) The employed materials must be abundant. (3) All the processes should not harm the environment.

Since the place, where the solar energy is rich and stably available, is limited to the place far from the area where the electricity is fully needed, it must be transported easily. Using the electrical cable for a long distance power supply crossing several countries is not practical because of huge construction cost and national security.

Considering that 10 billion fossil fuels are consumed in every year, huge amount of materials should be required to replace such energy.

Hydrogen might be one possibility, however energy density per volume is very small compared with gasoline even in the liquid form. For example, the density of liquid hydrogen is $70.8 \mathrm{~kg} / \mathrm{m}^{3}$ at the temperature of $20 \mathrm{~K}$ and reaction energy of hydrogen molecule is $120 \mathrm{MJ} / \mathrm{kg}$ and $8.5 \mathrm{GJ} / \mathrm{m}^{3}$ which should decrease if the container and cooling system down to $20 \mathrm{~K}$ are included. In contrast, reaction energy of gasoline is $50 \mathrm{MJ} / \mathrm{kg}$ and $39 \mathrm{GJ} / \mathrm{m}^{3}$, and that of magnesium is $25.2 \mathrm{MJ} / \mathrm{kg}$ and $43.8 \mathrm{GJ} / \mathrm{m}^{3}$.

Liquid methanol $(\mathrm{CH} 3 \mathrm{OH})$ as hydrogen carrier has the density of $793 \mathrm{~kg} / \mathrm{m}^{3}$ and includes hydrogen of $99 \mathrm{~kg} / \mathrm{m}^{3}$ that corresponds to $11.9 \mathrm{GJ} / \mathrm{m}^{3}$. However, it emits $\mathrm{CO} 2$ during the process and reaction speed is too slow. 


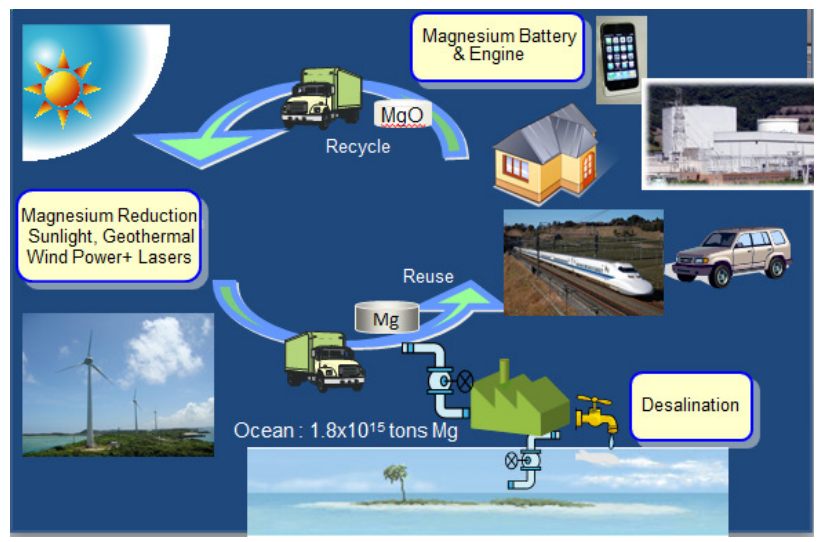

Figure 1 Magnesium recycling system.

We proposed to use magnesium as storing material [1] because it is abundant and resources in the ocean amounts up to 1.8 quadrillion tons. The reaction product is $\mathrm{MgO}$ or $\mathrm{Mg}(\mathrm{OH}) 2$ which are harmless and in solid state that can be easily collected. Only problem is how to produce and recycle it. We proposed to use lasers to recycle magnesium.

Magnesium compounds can be extracted either from the ocean or mine in solid form. These compounds are refined by using lasers as shown in Fig.1. The lasers are directly solar-energy-pumped laser ([2]-[7]) or semiconductor lasers pumped by electricity from various sources. Refined pure magnesium is used for mobile phone, automobile, and power reactor.

\section{Magnesium Fuel-Cell Battery}

\section{A. Film-Type Battery}

We proposed a new battery using magnesium. The battery is composed of reaction chamber and magnesium as shown in Fig.2. The magnesium is used in the form of thin film and is stored in the cartridge. After thin film is consumed in the reaction chamber, reaction products $\mathrm{Mg}(\mathrm{OH}) 2$ and/or $\mathrm{MgO}$ are moved away from the chamber and new film automatically enters into the chamber by winding the film using some mechanism like spring or small motor. By using such thin magnesium film, we demonstrated the battery capacity of $1300 \mathrm{Ah} / \mathrm{kg}$ which is 9 times larger than $150 \mathrm{Ah} / \mathrm{kg}$ of Lithium-Ion battery.

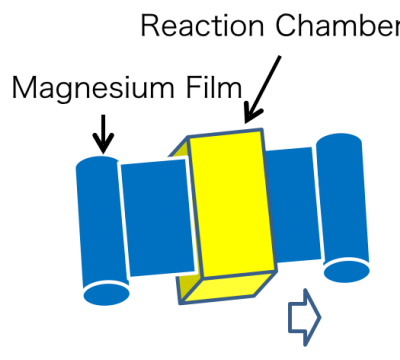

Move

Figure 2 Magnesium fuel-cell battery.
Conventional magnesium air battery uses thick plate of magnesium but after a thin surface layer is oxidized, rest of the part remains not reacted. This was the origin of low efficiency. Using thin layer of magnesium, however, almost all of the magnesium are fully used.

There are alternative methods to increase the efficiency using some chemical reaction to remove oxidized layer but without using film. However such reaction speed is always very slow compared with pure magnesium reaction. Therefore addition of slow reaction makes the output electric current very small. For example, only $0.5 \mathrm{~A}$ is achieved with $5 \mathrm{~cm} \times 5 \mathrm{~cm}$ magnesium in such thick plate scheme, while $10 \mathrm{~A}$ is achieved with the same area of thin film by our proposed new film method.

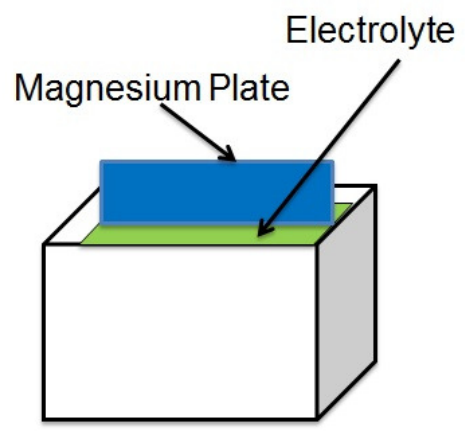

Figure 3 Conventional magnesium air battery.

In addition, using chemical reaction to remove oxidized layer leads to serious difficulties such that oxidized magnesium is mixed with electrolyte leading to degradation of conductivity. Therefore frequent replacement of electrolyte is required. In our case, oxidized layer can be held and moved away from the reaction chamber by some method and is not mixed with electrolyte. Since we only need the water that is responsible for reaction, the amount of electrolyte is similar to the amount of magnesium.

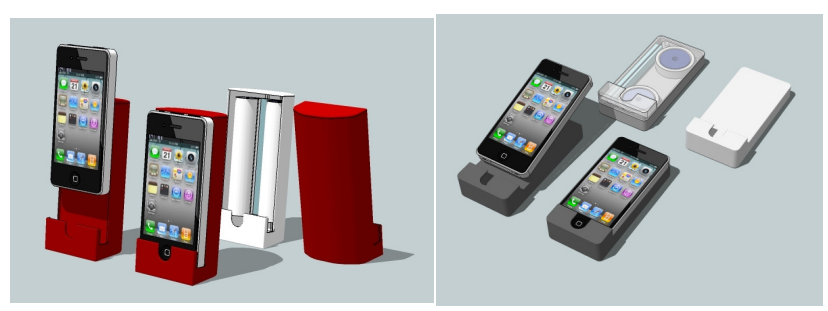

Figure 4 Magnesium fuel-cell battery is used as a cover and drives cell phone for a month without charging

\section{B. Battery for Cell Phone}

Since fuel of magnesium is outside of reaction chamber in our method, the size of whole battery is independent of battery capacity and hence any capacity can be realized by increasing the amount of magnesium. This is the typical feature of fuel-cell battery. Thus the battery 
becomes very compact. Let us consider a battery for cell phone. The capacity of conventional cell phone is $1500-$ $2000 \mathrm{mAh}$. Since we already achieved $1300 \mathrm{mAh} / \mathrm{g}, 30 \mathrm{~g}$ of magnesium can drive cell phone during one month without charging. The size of $30 \mathrm{~g}$ magnesium is a cylinder of $5 \mathrm{~mm}$-high and $6.6 \mathrm{~cm}$-diameter, and it can be installed inside cell phone.

\section{Battery for Automobile}

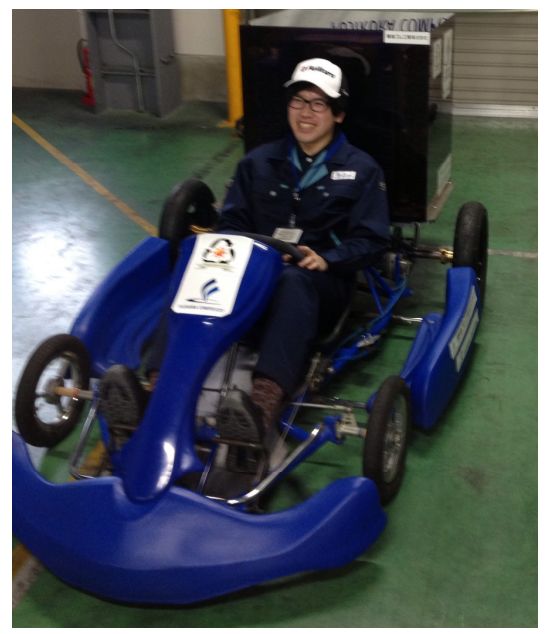

Figure 5 Magnesium fuel-cell battery for automobile whose total weight is $200 \mathrm{~kg}$. Collaboration with Fujikura Rubber Ltd.

For larger size, we already developed a cell that can deliver more than $20 \mathrm{~A}$ and $10 \mathrm{~W}$ whose cell area is $170 \mathrm{~mm}$ $x 340 \mathrm{~mm}$ and we shall develop a new cell of $300 \mathrm{~mm} x$ $600 \mathrm{~mm}$ that can deliver $60 \mathrm{~A}$ and $30 \mathrm{~W}$. By accumulating 100 of these cells, $3 \mathrm{~kW}$ model (peak power) will be finalized in 2014 with the size of $300 \mathrm{~mm} \times 600 \mathrm{~mm} \times$ $600 \mathrm{~mm}$. This size should be further reduced by improving battery efficiency and packing method. By this battery, we can drive an electric golf cart. 3 modules of this battery can drive a car for one person.

\section{Air Battery vs Magnesium Fuel-Cell Battery}

In the above discussion we only mentioned peak power. This is very interesting point of our battery. Conventional secondary battery needs to be charged and hence the stored energy like $\mathrm{kWh}$ is the key issue for comparison of its performance. The same discussion also applies to conventional "Air Battery" that uses thick plate of Mg.

In our film-type battery, which we call here "Magnesium Fuel-Cell Battery", the main battery system, reaction chamber, is separated from magnesium fuel in the form of film cartridge. This system is easily understood by comparing it with gasoline engine which has a combustion chamber and gasoline is stored in a tank. Our reaction chamber corresponds to the reciprocal engine and $\mathrm{Mg}$ fuel corresponds to gasoline. Therefore any distance mileage can be reached by increasing the amount of $\mathrm{Mg}$ fuel. This means the performance of fuel-cell battery is determined from its peak power like $\mathrm{kW}$ or PS and $\mathrm{kWh}$ does not depend on the reaction chamber but on fuel amount. Thus most prominent feature of our battery that distinguishes it from other $\mathrm{Mg}$ air batteries is that fuel part is separated from reaction part.

\section{Magnesium Recycling by Lasers}

Reaction product in magnesium battery is refined back to pure magnesium by lasers. Using $1 \mathrm{~kW} \mathrm{CO} 2$ laser, we already succeeded in producing $15 \mathrm{mg} / \mathrm{kJ}$ [9] and $20 \mathrm{mg} / \mathrm{kJ}$ with $4 \mathrm{~kW}$ semiconductor laser. This means $50 \mathrm{~kJ}$ is used to get $1 \mathrm{~g}$ of magnesium. Since magnesium of $1 \mathrm{~g}$ releases the energy of $25.2 \mathrm{~kJ}$, the above efficiency of magnesium recovery is $50 \%$. Currently we have $8 \mathrm{~kW}$ semiconductor laser which can produce 5 tons of magnesium per year. Since magnesium battery reached $60 \%$ of theoretical limit $7 \mathrm{kWh} / \mathrm{kg}$ in laboratory experiment, magnesium of $24 \mathrm{~kg}$ generate $100 \mathrm{kWh}$ sufficient for $500 \mathrm{~km}$ mileage of medium-sized car. Therefore $8 \mathrm{~kW}$ laser can support 208 cars $x 500 \mathrm{~km}$ mileage in one year

$8 \mathrm{~kW}$ laser that can provide 5 tons of magnesium/year can support the battery for 13,000 cell phones in one year. If 3 billion people use magnesium battery for cell phones, we need to produce magnesium of 1 million tons every year. Since current magnesium production is 0.6 million tons/year, we need to establish magnesium production plants before selling cell phone battery.

For commercial plant, we can start with the combination of wind power generator, geothermal power plant, hydraulic power plant and semi-conductor lasers. Solar pumped laser should come later after the output reaches $400 \mathrm{~W}$ because it is cheap and directly uses solar energy. The latest maximum output from solar pumped laser is $120 \mathrm{~W}$ and $400 \mathrm{~W}$ is within a reach as shown in the next section.

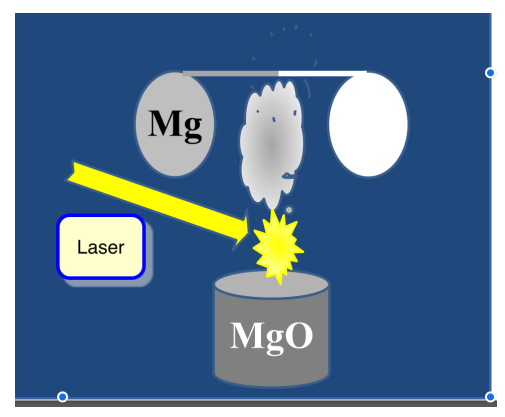

Figure 6 After laser illumination, magnesium is separated from $\mathrm{MgO}$ and evaporated magnesium reaches film and is coated on it.

There is another advantage in using laser. As shown in Fig.6, when high intensity laser illuminates $\mathrm{MgO}, \mathrm{MgO}$ is disintegrated into magnesium and oxygen, which are ablated with high speed. If we put a thin substrate film, it is coated with the magnesium of more than 10 micron thickness. If the substrate is gradually moved during ablation, roll film of magnesium is automatically produced. Thus magnesium refinement and fuel production can be simultaneously performed. 


\section{Solar-Energy-Pumped Laser}

\section{A. Primary Solar Concentrator}

Most of studies([2]-[6]) on solar-pumped laser employed traditional concentrators such as a parabolic mirror, heliostat, and Fresnel lens as the primary concentrator. Among them, a high reflectivity mirror system provides a higher focusing efficiency without chromatic dispersion, while a Fresnel lens is more economical [1].

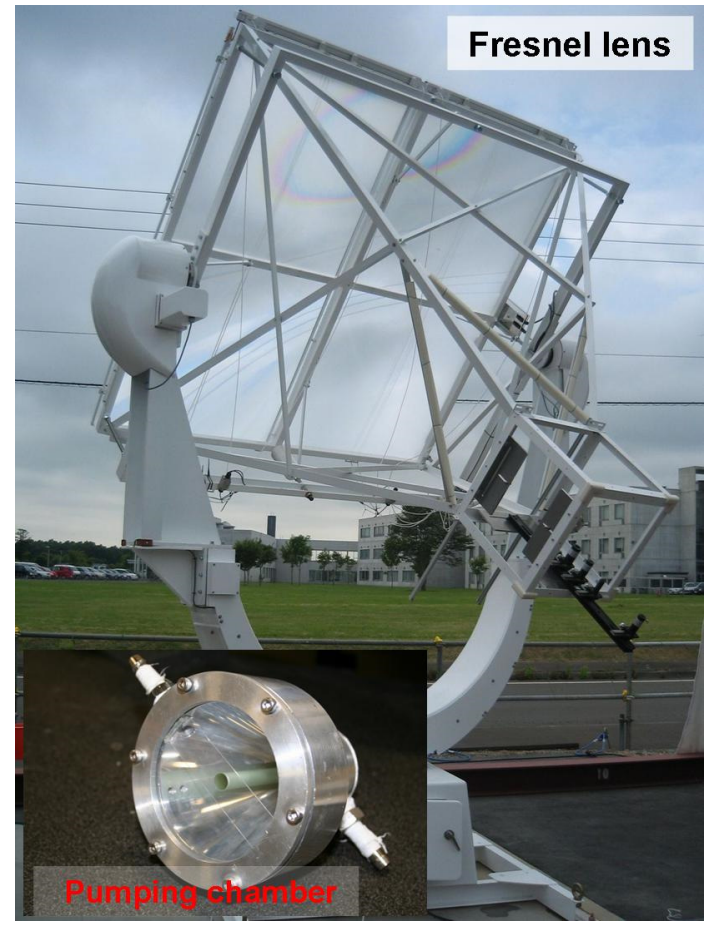

Figure 7 Primary solar concentrator that uses Fresnel lens and pumping cavity made of aluminum.

In this study, a 2×2-m Fresnel lens with 2-m focal length was designed for the primary concentrator. As shown in Fig. 7, it is mounted on an automatic solar tracker to follow the sun's movement. The Fresnel lens is made of Poly methyl methacrylate (PMMA), which is transparent at visible and near infrared (IR) wavelengths, and blocks ultraviolet (UV) solar radiation below about $390 \mathrm{~nm}$ and IR of longer wavelengths than $2200 \mathrm{~nm}$. The measured full width at half maximum (FWHM) of solar spot at focal point of the Fresnel lens is $20.4 \mathrm{~mm}$, while the ideal focused sum image without chromatic dispersion should be $18.6 \mathrm{~mm}$ [7]

Focusing efficiency of the Fresnel lens could reach $80 \%$ by our ray tracing simulation. Unfortunately, however, the measured value is only $50 \%$ because of some bubbles and scarring on its surface created in the manufacturing process. In fact, the higher efficiency has been realized with less than $1 \mathrm{~m}$-diameter Fresnel lenses ([1],[10]).

\section{B. Secondary Concentrator}

The laser cavity, which we call the second concentrator, is located at the focal zone of the Fresnel lens. $\Phi 6 \times 100-$ $\mathrm{mm} \mathrm{Nd}$ :YAG rod is employed in order to minimize the thermal effect.

The secondary concentrator is a conical mirror as shown in Fig.7 that realizes the hybrid-pumping scheme. It is used to confine the collected solar power by multi reflections, and focus it into laser medium. In experiments, the conical concentrators are made of aluminum. The inner walls are hand-polished or bonded with a protected silver-coated aluminum foil whose reflectivity measured at $632 \mathrm{~nm}$ wavelength of them is about $70 \%$ or $90 \%$, respectively. However, the aluminum foil will easily be damaged under intense solar radiation condition, if there is no cooling treatment.

In order to improve the efficiency, the liquid light-guide lens (LLGL), that has the structure of a cylinder of coolant sheathing the laser rod and has the additional focusing effect provided by the difference of refraction index between the air and coolant, was adopted [8]. The LLGL, however, must adopt hand-polished cavity because the inner wall of cavity cannot be effectively cooled at present.

The solar input aperture $\Phi_{1}$ of the second concentrators must be large enough to compensate the chromatic dispersion and the corner effect of the square Fresnel lens. Although the solar radiation at ground has a spectrum from 280 to $4000 \mathrm{~nm}$, a Nd:YAG medium can converted only the spectrum below $870 \mathrm{~nm}$ into $1064 \mathrm{~nm}$ laser wavelength due to its four level laser system. The threedimensional ray-tracing calculation shows that for $\Phi_{1}=$ $80 \mathrm{~mm}$ input diameter, the second concentrator can receive about $96 \%$ of the collected solar power which is valid for lasing.

Figure 8 shows the experimental results of laser output for various incident solar power for the LLGL enhanced laser cavity.

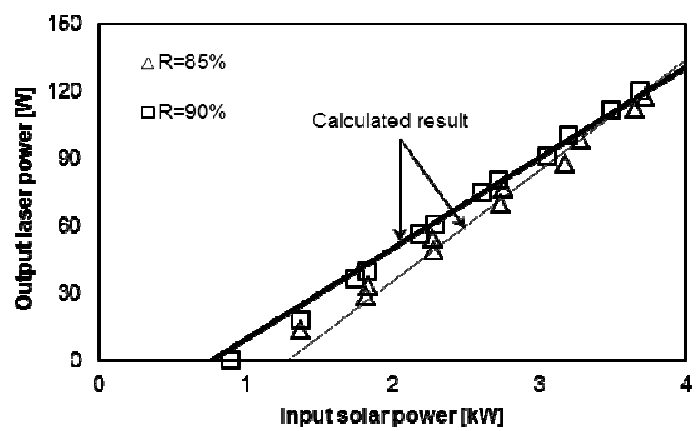

Figure 8. Calculated (lines) and experimental (symbols) results of output laser power for $\Phi 6 \times 100-\mathrm{mm} \mathrm{Nd}$ :YAG rod which was pumped by $70 \%$ reflectivity hybrid concentrator and 14-mm diameter LLGL. $R$ is the reflectivity of output coupler. The thin and thick line are calculated results of $R=90 \%$ and $R=85 \%$ respectively, 


\section{Conclusion}

We proposed the renewable energy cycle to use the magnesium as container of solar energy. The magnesium fuel-cell battery is demonstrated by small car and cell phone. By this battery, we can use the smartphone for a month without charging. The magnesium fuel-cell battery is analogous to gasoline engine, that is, reaction chamber and fuel are separated, and hence by increasing fuel it can drive a car for a long distance.

Recycling of reacted magnesium can be performed by semiconductor laser and solar-energy-pumped laser.

\section{References}

[1] T.Yabe et.al., "Demonstrated fossil-fuel-free energy cycle using magnesium and laser", Appl.Phys.Lett. 89 (2006) 261107-1-3

[2] C. G. Young, "A sun-pumped cw one-watt laser," Appl. Opt. (1966), Vol.5(6), pp.993-997.

[3] H. Arashi, Y. Oka, N. Sasahara, A. Kaimai, and M. Ishigame, "A solar-pumped cw 18W Nd:YAG laser,” Jpn. J. Appl. Phys. (1984), Vol.23(Part 1, No. 8), pp.1051-1053.
[4] Dave Cooke, "Sun-pumped lasers: revisiting an old problem with nonimaging optics," Appl. Opt. (1992), Vol.31, p.7541.

[5] V. Krupkin, Y. Kagan, and A. Yogev, "Nonimaging optics and solar laser pumping at the Weizmann Institute," Proc. SPIE 2016 50 (1993).

[6] M. Lando, J. Kagan, B. Linyekin, and V. Dobrusin, "A solarpumped Nd:YAG laser in the high collection efficiency regime," Opt. Commun. (2003), Vol.222, p.371 .

[7] T. Ohkubo, T. Yabe, K. Yoshida, S. Uchida, T. Funatsu, B. Bagheri, T. Oishi, K. Daito, M. Ishioka, Y.Nakayama, N. Yasunaga, K. Kido, Y. Sato, C. Baasandash, K. Kato, T. Yanagitani, and Y. Okamoto, "Solar pumped $80 \mathrm{~W}$ laser irradiated by a Fresnel lens," Opt. Lett. (2009), Vol.34(2), pp.175-177.

[8] T. H. Dinh, T. Ohkubo and T. Yabe, "120 watt continuous wave solar-pumped laser with a liquid light-guide lens and an Nd:YAG rod", Optics Letters, (2012)Vol. 37, pp.2670-2672

[9] S. H. Liao, T. Yabe et.al.,'Laser-induced Mg production from magnesium oxide using Si-based agents and Si-based agents recycling", J.Appl.Phys.(2011),Vol.109 , 013103

[10] Dawei Liang, and Joana Almeida, "Highly efficient solar-pumped Nd:YAG laser,” Opt. Express(2011), Vol.19, p.26399. 